\title{
WORKSHOP PEMBELAJARAN DARING MENGGUNAKAN GOOGLE CLASSROOM PADA SMK SULTHAN MUAZZAM SYAH PEKANBARU
}

\author{
Yoyon Efendi ${ }^{1}$, Lusiana ${ }^{2}$, Rometdo Muzawi ${ }^{3}$, Unang Rio ${ }^{4}$, Wirta Agustin ${ }^{5}$ \\ 1, 2,3,4,5STMIK Amik Riau, Pekanbaru, Indonesia \\ email: 1yoyonefendi@stmik-amik-riau.ac.id, ${ }^{2}$ lusiana@stmik-amik-riau.ac.id, \\ 3rometdomuzawi@stmik-amik-riau.ac.id, ${ }^{3}$ unangrio@stmik-amik-riau.ac.id, \\ 5wirtaagustin@stmik-amik-riau.ac.id
}

\begin{abstract}
Abstrak: Masalah pembelajaran sering menjadi alasan guru-guru tidak maksimal memberikan materi di kelas. Seperti Susana COVID 19 pada saat ini selain itu juga dengan berbagai alasan seperti guru lagi rapat, dinas luar kota menjadi halangan guru menyampaikan materi di sekolah bahkan siswa berkeliaran dan rebut dikelas. Diperlukan media pembelajaran yang efektif dan efisien bagi guru untuk tetap menyampaikan materi walau dalam kondisi apapun. Pembelajaran menggunakan Google Classroom, salah satu cara untuk menghadapi tantangan dunia teknologi pada bidang pendidikan melalui media pembelajaran. Workshop ini diikuti oleh 13 orang guru-guru dari kota Pekanbaru seperti SMK Negeri 2 Pekanbaru, SMK Bina profesi dan SMK Sulthan Muazzam Syah. Setelah melalui Pre-test dan Post-test terjadi peningkatan pengetahuan dan keahlian guru dalam mengelola kelas pada Google Classroom. Workshop ini dapat menjadi bekal dalam kegiatan belajar mengajar di sekolah maupun luar sekolah.
\end{abstract}

Kata Kunci: Workshop, Pembelajaran, Daring, Classroom, SMK Sulthan Muazzam Syah

\begin{abstract}
Learning problems are often the reason teachers are not optimal in providing material in class. Like Susana COVID 19 at the moment, besides that, for various reasons, such as teachers having meetings, out-of-town offices are an obstacle for teachers to deliver material at school, even students wandering around and fighting in class. An effective and efficient learning media is needed for teachers to continue to deliver material even under any conditions. Learning using Google Classroom, one way to face the challenges of the world of technology in the field of education through learning media. This workshop was attended by 13 teachers from the city of Pekanbaru, such as SMK Negeri 2 Pekanbaru, SMK for professional development and SMK Sulthan Muazzam Syah. After going through the Pre-test and Post-test there was an increase in the knowledge and expertise of teachers in managing classes in Google Classroom. This workshop can be a provision in teaching and learning activities at school and outside school.
\end{abstract}

Keywords: Workshop, Learning, Online, Classroom, SMK Sulthan Muazzam Syah

\section{Pendahuluan}

SMK Sulthan Muazzam Syah terletak di jalan kartama Pekanbaru memiliki 3 program keahlian yaitu Teknik Komputer Jaringan (TKJ), Teknik Sepeda Motor (TSM) dan Akuntansi. SMK ini memiliki 89 siswa dan 12 guru yang tersebar ke 3 program keahlian tersebut.

Sekolah ini berusaha meningkatkan kualitas tenaga pengajar dengan menfasilitasi kegiatan-kegiatan dalam kondisi daring seperti Google Classroom, salah satunya dalam media pembelajaran. Media pembelajaran merupakan pilar yang sangat penting pada sebuah sekolah.

Dengan meningkatnya pengetahuan guru akan berdampak positif dalam kegiatan belajar mengajar walaupun dalam kondisi apapun. Seperti guru rapat, dinas keluarga, dan 
sebagainya. Tidak ada alasan tidak masuk kelas dan tidak memberikan alasan tidak membagikan materi walaupun dari rumah sekalipun.

Berdasarkan paparan pada analisa situasi masalah yang dihadap dapat diidentifikasi sebagai berikut: pertama, Rendahnya pengetahuan guru dalam Media Pembelajaran. Kedua Rendahnya guru dalam teknologi Pembelajaran. Ketiga Kurangnya guru dalam penggunaan aplikasi pembelajaran google classroom

Berdasarkan identifikasi di atas maka dapat dirumuskan masalah yang di hadap sebagai berikut: pertama, Bagaimana guru dapat mengetahui konsep Media pembelajaran google classroom dengan baik?. Kedua Bagaimana guru dapat menggunakan aplikasi classroom secara efektif dan efisien?. Ketiga, Bagaimana guru dapat menerapkan dalam kegiatan belajar mengajar dengan aplikasi classroom yang baik

Tujuan yang ingin di capai dalam kegiatan ini diantaranya adalah : pertama, Meningkatkan pengetahuan tentang Goole Classroom bagi guru di SMK Sulthan Muazzam Syah Pekanbaru. Kedua, Peserta mampu mengerjakan kelas dengan Goole Classroom dengan studi kasus sekolah. Ketiga, Peserta memahami dan mengerti konsep dan aplikasi google classroom. Keempat, Peserta dapat menggunakan media pembelajaran lainnnya untuk diterapkan di sekolah.

Adapun manfaat kegiatan pengabdian masyarakat ini adalah sebagai berikut : pertama, Kegiatan ini diharapkan dapat memacu minat guru dalam mempelajari media pembelajaran Goole Classroom dengan baik dan benar. Kedua, Kegiatan ini diharapkan peserta mampu mengaplikasikan dalam kegiatan sekolah seperti pembelajaran, nilai, latihan dan tugas.

Pada saat sekarang ini guru dituntut untuk menguasai teknologi guna memberikan kemudahan kepada siswa dalam belajar(Efendi et al., 2021). Media pengajaran merupakan wadah dan penyalur pesan dari sumber pesan, dalam hal ini guru, kepada penerima pesan, dalam hal ini siswa. Dalam batasan yang lebih luas, menurut Yusufhadi Miarso memberikan batasan media pengajaran sebagai segala sesuatu yang dapat digunakan untuk merangsang pikiran,perasaan, perhatian, dan kemauan siswa sehingga mendorong terjadinya proses belajar pada diri siswa. Ada beberapa media e-learning seperti googleclassroom, moodle dan edmodo. Googleclassroom, khusus e-learning merupakan salah satu dari Google Aps For Education (GAFE)(Efendi \& Utami, 2019)

Salah satu metode pembelajaran online yang saat ini sedang berkembang dan mulai digunakan adalah google classroom. Google Classroom adalah aplikasi yang dikhususkan untuk media pembelajaran online atau istilahnya adalah kelas online sehingga dapat memudahkan guru dalam membuat, membagikan serta mengelompokkan setiap tugas tanpa menggunakan kertas lagi(Soni et al., 2018).

Google Classroom merupakan sebuah aplikasi yang memungkinkan terciptanya ruang kelas didunia maya. Selain itu, google classroom bisa menjadi sarana distribusi tugas, submit tugas bahkan menilai tugas-tugas yang dikumpulkan(Nirfayanti \& Nurbaeti, 2019). Melalui aplikasi Google Classroom diasumsikan bahwa tujuan pembelajaran akan lebih mudah direalisasikan dan sarat kebermaknaan. Oleh karena itu, penggunaan Google Classroom ini sesungguhnya mem- permudah guru dalam mengelola pembelajaran dan 
menyampaikan informasi secara tepat dan akurat kepada peserta didik(Sabran \& Sabara, 2019).

\section{Metode}

Pendekatan yang digunakan pada pengabdian masyarakat di Sulthan Muazzam Syah Pekanbaru adalah Materi di lengkapi dengan modul, project mobile, video tutorial dan studi kasus. Pemecahan Masalah melalui presentasi konsep pembelajaran google classroom untuk mendukung pemahaman peserta pelatihan di dampingi oleh Tutor yang berpengalaman.

Pendekatan cara pemecahan msalah yang dilakukan yaitu:

1. Memberikan motivasi kepada peserta pelatihan

2. Menggali pengetahuan peserta akan media pembelajaran (pre-test)

3. Konsistensi materi pelatihan

4. Mengajak peserta untuk aktif dalam pelatihan

5. Pratikum sebagai penerapan google classroom

6. $\quad$ Evaluasi pelatihan sebagai tolak ukur hasil luaran(post-test)

7. Efisiensi biaya dinas luar kota

Pelatihan tersebut diberikan langsung oleh tim dosen STMIK Amik Riau di Sulthan Muazzam Syah Pekanbaru. Media pelatihan yang digunakan adalah sebagai berikut:

1. Media proyektor dan laptop untuk menampilkan secara visual mengenai materi pelatihan yang akan dissampaikan.

2. Laser pointer, yang digunakan untuk memberikan kesan lebih interaktif dalam menyajikan bahan pelatihan bagi guru, sehingga lebih dapat memunculkan semangat bagi guru dalam kegiatan pelatihan.

3. Modul pratikum dilengkapi contoh - contoh studi kasus.

Pada bagian metode penerapan, uraikanlah dengan jelas dan padat metode yang digunakan untuk mencapai tujuan yang telah dicanangkan dalam kegiatan pengabdian. Hasil pengabdian itu harus dapat diukur dan penulis diminta menjelaskan alat ukur yang dipakai, baik secara deskriptif maupun kualitatif. Jelaskan cara mengukur tingkat ketercapaian keberhasilan kegiatan pengabdian. Tingkat ketercapaian dapat dilihat dari sisi perubahan sikap, sosial budaya, dan ekonomi masyarakat sasaran.

\section{Hasil dan Pembahasan}

Hasil Evaluasi terhadap kegiatan Workshop pembelajaran daring menggunakan Google Classroom di SMK Sulthan Muazzam Syah Pekanbaru dengan meningkatnya pengetahuan guru dalam pembelajaran Google Classroom.

Workshop ini memberikan sesi pratikum dan evaluasi hasil pembelajaran menggunakan Google classrom oleh guru-guru SMK Sulthan Muazzam Syah Pekanbaru. Hasilnya terjadi peningkatan pengetahuan dan keahlian guru-guru menggunakan Google Classroom melalui Pre-test dan Post-test seperti terlihat pada tabel 1 sebagai berikut: 
Tabel 1. Tabel Pre-test dan post-test peserta workshop

\begin{tabular}{clclc}
\hline No. & \multicolumn{2}{c}{ Pre-Test } & \multicolumn{2}{c}{ Post-Test } \\
\hline & Jawaban & Jumlah & Jawaban & Jumlah \\
\hline 1 & Benar 0 & 3 & Benar 0 & 0 \\
2 & Benar 1 & 1 & Benar 1 & 0 \\
3 & Benar 2 & 0 & Benar 2 & 0 \\
4 & Benar 3 & 0 & Benar 3 & 0 \\
5 & Benar 4 & 1 & Benar 4 & 0 \\
6 & Benar 5 & 3 & Benar 5 & 0 \\
7 & Benar 6 & 3 & Benar 6 & 0 \\
8 & Benar 7 & 0 & Benar 7 & 0 \\
9 & Benar 8 & 0 & Benar 8 & 0 \\
10 & Benar 9 & 0 & Benar 9 & 1 \\
11 & Benar 10 & 0 & Benar 10 & 12 \\
\hline
\end{tabular}

Dari 13 orang peserta yang terdiri dari guru- guru SMK Bina Profesi, SMK N 2 Pekanbaru dan SMK Sulthan Muazzam Syah Pekanbaru untuk menghadiri pengabdian kepada masyarakat " Workshop pembelajaran daring menggunakan Google Classroom di SMK Sulthan Muazzam Syah Pekanbaru". Setelah pelaksanaan pelatihan, nampak peningkatan pengetahuan guru-guru secara signifikan. Terlihat semua peserta mampu menyelesaikan tugas pratikum yang diberikan. Oleh sebab itu diharapkan peserta pelatihan dapat memanfaatkan pengetahuan ini untuk mampu mengembangkan diri dalam pembelajaran google classroom.

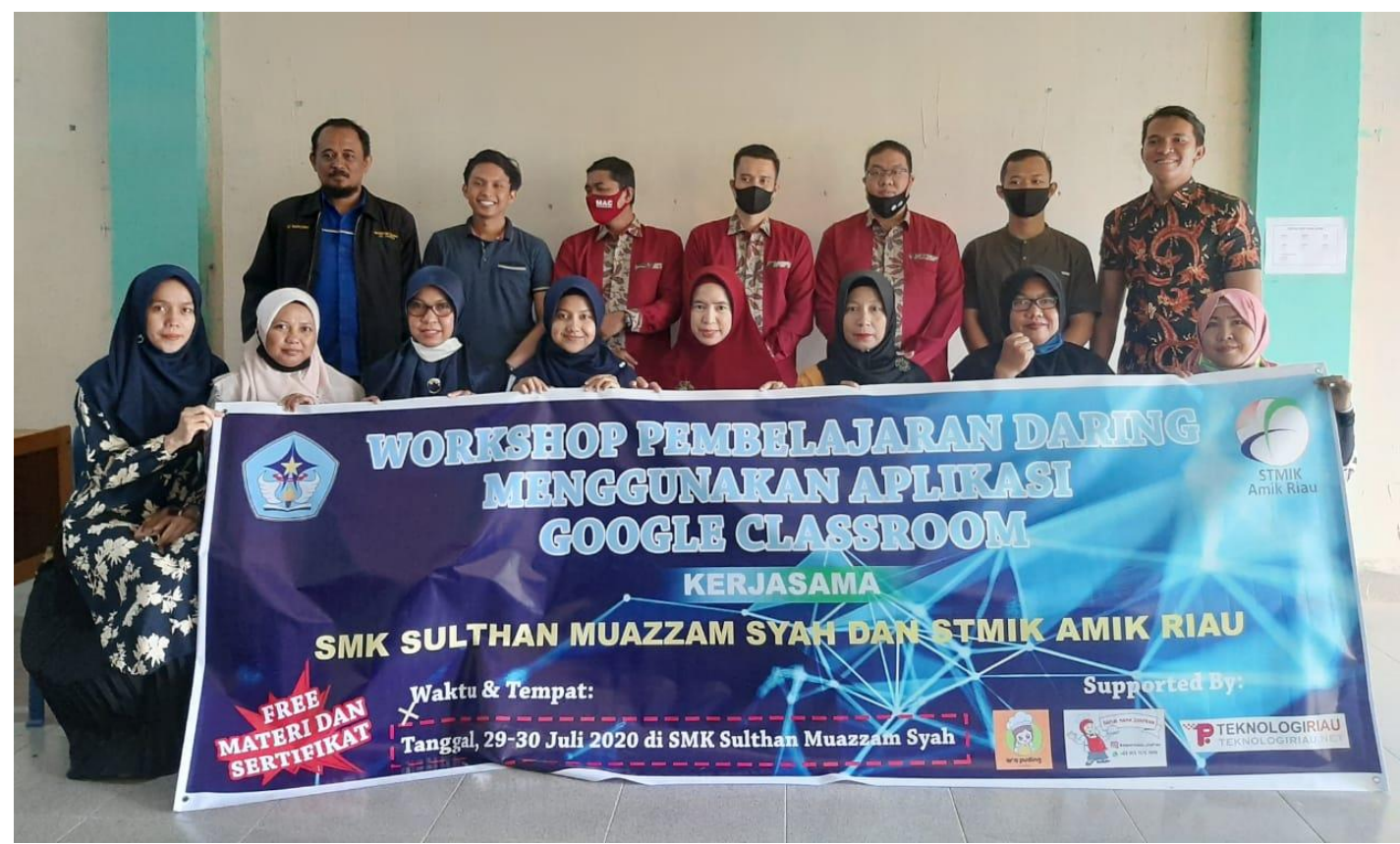

Gambar 1. Foto bersama peserta dan tim dosen 


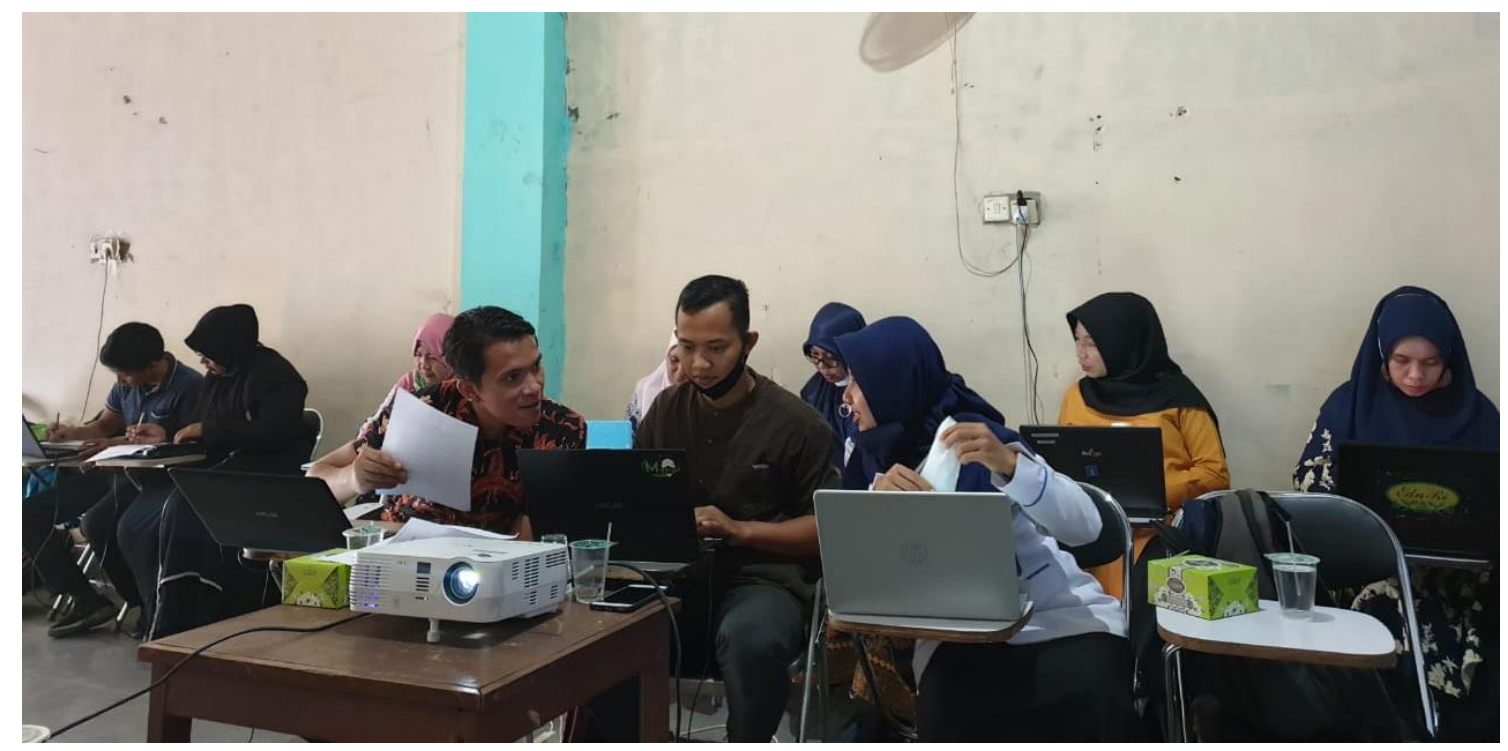

Gambar 1. Peserta dari guru-guru SMK

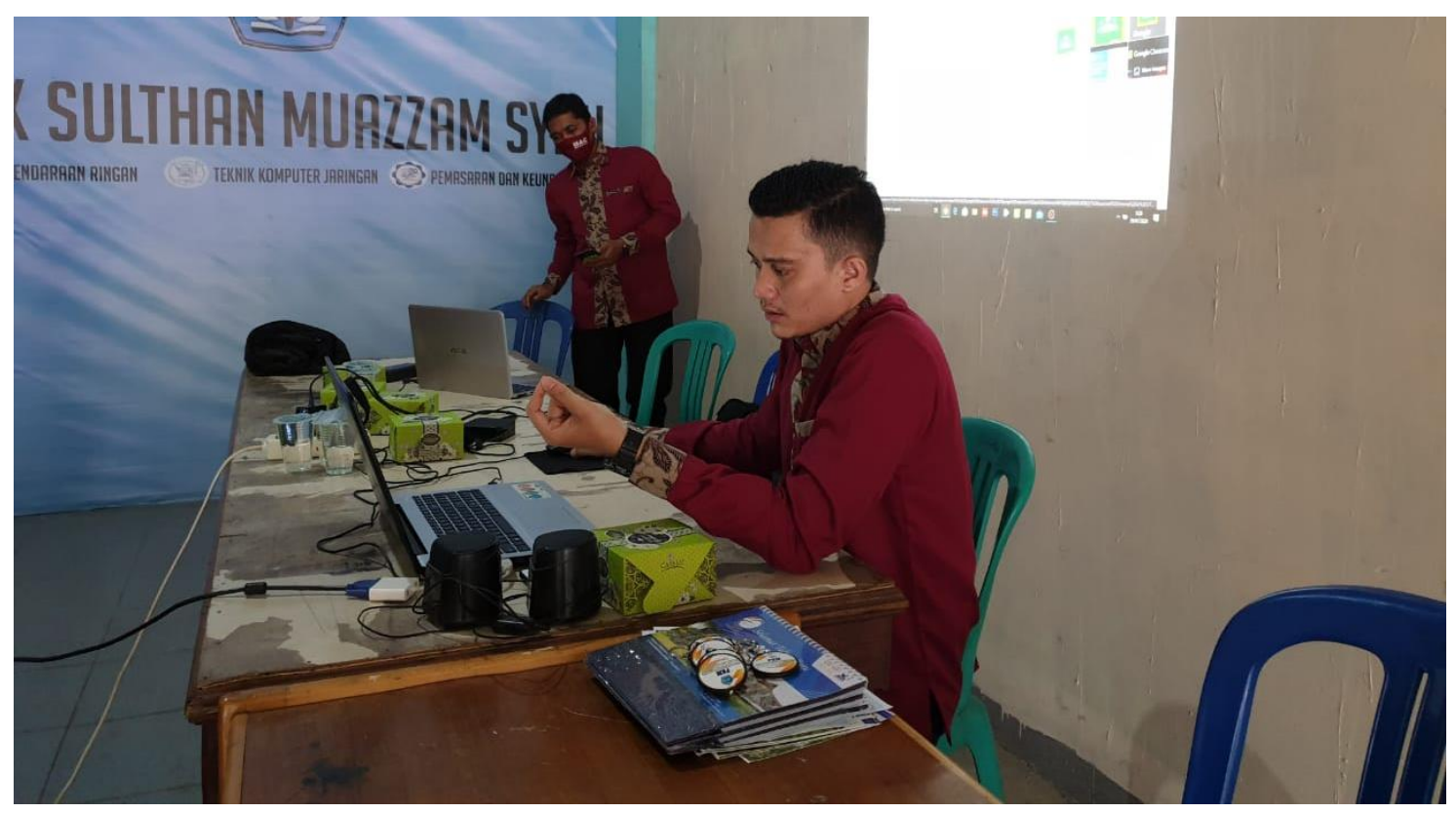

Gambar 3. Tim dosen memberikan materi

\section{Kesimpulan}

Berdasarkan hasil pelaksanaan kegiatan yang telah dilakukan, dapat ditarik kesimpulan sebagai berikut:

1. Menjadi sekolah dalam penerapan pembelajaran google Classroom .

2. Dengan adanya workshop akan menumbuhkan semangat belajar menggunakan google classroom dalam lingkungan sekolah secara baik dan sempurna.

3. Dapat menarik minat guru dalam mendongkrak popularitas sekolah sebagai satusatunya sekolah berbasis teknologi dalam kegiatan Belajar Mengajar (KBM).

4. Meningkatkan minat guru dalam mengembangkan dan melanjutkan media pembelajaran lainnya di sekolah dan di luar sekolah. 
Dalam rangka meningkatkan kualitas dan kuantitas pelaksanaan acara sejenis kiranya dapat memperhatikan saran berikut:

1. Diperlukan pelatihan media pembelajaran lanjutan untuk mengasah minat dan kemampuan guru dengan lebih dalam.

2. Diperlukan perangkat penunjang pelatihan teknologi pembelajaran yang lebih baik dan koneksi internet yang lebih stabil.

\section{Daftar Pustaka}

Efendi, Y., Lusiana, L., Muzawi, R., Yanti, R., \& Imardi, S. (2021). Workshop E-Learning Google Classroom Dan Video Pembelajaran Pada Smp N 35 Pekanbaru. Mitra Mahajana: Jurnal Pengabdian Masyarakat, 2(1), 82-89. https://doi.org/10.37478/mahajana.v2i1.789

Efendi, Y., \& Utami, N. (2019). Pengukuran Efektifitas Pembelajaran Menggunakan Media E-Learning Google Classroom ( SMK Sulthan Muazzamsyah Pekanbaru ). Prosiding Seminar Nasional Computation Technology and Its Aplication, 1(1), 1-4. https://ejurnal.umri.ac.id/index.php/CTIA/article/view/1822

Nirfayanti, N., \& Nurbaeti, N. (2019). Pengaruh Media Pembelajaran Google Classroom Dalam Pembelajaran Analisis Real Terhadap Motivasi Belajar Mahasiswa. Proximal, 2(1), 50-59. https://doi.org/https://doi.org/10.30605/2615-7667.211

Sabran, \& Sabara, E. (2019). Keefektifan Google Classroom sebagai media pembelajaran. PROSIDING SEMINAR NASIONAL LEMBAGA PENELITIAN UNIVERSITAS NEGERI Makasar, 122-125.

https://webcache.googleusercontent.com/search?q=cache:SS_jKM_r2TAJ:https:// ojs.unm.ac.id/semnaslemlit/article/download/8256/4767+\&cd=2\&hl=id\&ct=clnk\&g I=id

Soni, Hafid, A., Hayami, R., Fatma, Y., Wenando, F. A., Amien, J. Al, Fuad, E., Unik, M., Mukhtar, H., \& Hasanuddin. (2018). Optimalisasi Pemanfaatan Google Classroom Sebagai Media Pembelajaran Di SMK Negeri 1 Bangkinang. Jurnal Pengabdian Untuk Mu NegeRI, 2(1), 17-20. https://www.researchgate.net/publication/331703602\%0AOPTIMALISASI 